\title{
29 Establishing effective school and community collaborations to prevent student homelessness
}

\author{
Monica Thielking
}

\section{How to use this policy}

This policy is designed to provide schools with evidence-based strategies to establish school and community collaborations to prevent youth homelessness. This policy example is intentionally broad and school policy creators are encouraged to delete and build upon suggestions below to create a policy that best represents their school.

[To adapt and use this policy, delete or modify the text as indicated]

\section{[INSERT name of school] Prevention of student homelessness policy}

\section{Rationale}

The conditions that ensure the wellbeing of children and young people around the world are reinforced by the United Nations Convention on the Rights of the Child (Office of the United Nations High Commissioner for Human Rights [UNHCR],1989) and the Universal Declaration of Human Rights (United Nations General Assembly, 1948). Article 25 of the Universal Declaration of Human Rights affirms that secure housing, health and wellbeing are intertwined.

The prevalence of children and young people who experience homelessness around the world is difficult to estimate due to the multifaceted nature of youth homelessness and a lack of universal data collection methods. What we do know is that youth homelessness is a global issue, is rising and is becoming more apparent in the form of family homelessness (OECD, 2020). According to the Institute for Children, Poverty and Homelessness ([ICPH], 2020) in 2019, 1.35 million children in American public schools were estimated to be homeless. In Australia, children aged 0-14 make up 17\% of the homeless population (Australian Bureau of Statistics, 2016) and are defined as being homeless.

When students are living in supported accommodation designed for people in a state of homelessness (including women's refuges or youth refuges), then schools are usually informed of this. However, there is a hidden form of student homelessness, which schools may either be unaware of or be the first to notice. This form of homelessness is common to youth and involves staying at friends' 


\section{Thielking}

houses or moving between other untenured temporary forms of accommodation. It is informally referred to as couch-surfing or doubling-up in the international literature (McLoughlin, 2013). Research reveals that some children and young people begin running away as early as age 10 and may even have short or prolonged periods of rough sleeping (Flatau et al., 2015). This means that efforts to prevent student homelessness should begin as early as possible in the child's development, with some suggesting as early as preschool (e.g., Gultekin et al., 2020).

Irregular school attendance (e.g., Moore \& McArthur, 2011), underachievement and learning difficulties (e.g., ICPH, 2019), risk-taking behaviours (e.g., binge drinking, Cutuli, 2018), behavioural issues (e.g., Cutuli, 2018) and early school leaving (e.g., Low, Hallett, \& Mo, 2017) are common presentations among homeless students. Furthermore, homelessness in children and adolescents is associated with multiple negative physical health, mental health and behavioural outcomes (Gultekin et al., 2020).

A troubled home life is the most common precursor to youth homelessness (National Youth Commission, 2008). Two risk factors include being in out-ofhome care and experiencing family violence, and high rates of psychological distress and suicidal ideation or attempts are reported among such youth (Flatau et al., 2015). A history of abuse is common within this cohort (Tyler \& Schmitz, 2020), as well as high involvement with the child protection system (Hong \& Piescher, 2012). It is therefore critical that teachers and other school staff are competent in trauma-informed practices when supporting students who are homeless or are at risk of homelessness (Luthar \& Mendes, 2020).

Schools play a vital role in the detection and prevention of student homelessness; however, research shows that many young people who are facing extreme family issues that lead to homelessness do not seek help, and the majority will still attend school whilst being in the "in and out of home" stage, often without the knowledge of teachers or peers (Thielking et al., 2015). School may represent a safe and consistent place for students living in difficult situations (Bernard, 1997) and a positive school climate is associated with better outcomes for school-attending homeless youth (Moore, Benbenishty, Astor, \& Rice, 2018). Unfortunately, for many students in this situation, conditions at school can also serve to increase negative outcomes, as homeless students are more likely to experience school violence and victimisation (Moore et al., 2019).

Early intervention is a key preventative factor for student homelessness, and due to the complexity of factors that lead up to students running away from home and the impact of homelessness on students, schools cannot deal with this issue alone. In addition to integrated within-school inter-professional relationships to support homeless students (Stone \& Charles, 2018), it is vital that schools also have strong partnerships with community-based youth services when supporting students (Sanders \& Brown, 2015). The key ingredients of effective inter-service collaborations involve a combination of leadership and resourcing to support such partnerships in service delivery 
(Williams \& Sullivan, 2009). A study of school wellbeing and staff collaboration in and between schools and community agencies revealed that drivers to collaboration included:

- Open communication practices and resource sharing

- Common values, respect and putting students' needs at the centre of collaboration

- Regular, structured team meetings to support collaborative practice

Barriers to collaboration in and between schools and community agencies included:

- Time restrictions and a sense of being too busy to collaborate

- Practical barriers that stopped school staff from accessing local agencies

- Collaboration not being valued by one or more parties

- Lack of understanding of roles

- Differing professional and ethical practices (Thielking et al., 2018)

Financial and mobility barriers for families and/or students may also prevent service access. The external provision of services should be delivered in an easily accessible location, and for some communities, this may be the school (Sulkowski \& Michael, 2014). Furthermore, while teachers play a significant role in providing support to students, they may be unsure about what to do or who to turn to when responding to student homelessness, including whether to notify child protection services (Thielking et al., 2017). There is a need for school policies that promote formalised collaborations with relevant service providers in order to facilitate professional development and support of teachers, seamless school-community partnerships and the linking in of families and students to appropriate services.

\section{Purpose}

The purpose of this policy is to demonstrate that [INSERT name of school] is committed to establishing effective school and community collaborations to provide early intervention and prevent student homelessness.

\section{Scope}

This policy applies to school leadership, student wellbeing and teaching staff of [INSERT name of school].

[INSERT specific roles and responsibilities of individuals or teams]

\section{Policy statement}

When students are identified as experiencing homelessness or are at risk of homelessness, [INSERT name of school] is committed to ensuring students are 


\section{Thielking}

safe, that they receive the specialist and professional support they require to remain at home or in supportive housing and that they remain at school and achieve educational success. [INSERT name of school] understands its statutory obligations in relation to protecting children and young people from neglect, maltreatment and abuse and will notify and work with authorities to ensure all students are safe from harm. Where possible, families and/or students will be involved in these processes.

\section{Early identification of students experiencing or at risk of experiencing homelessness}

Teachers play a significant role in the early identification of student homelessness and recognise that children as young as 10 have been shown to run away from home, especially when there is a high level of family conflict (Flatau et al., 2015). However, students who are running away from home or couchsurfing/doubling-up may actively conceal their situation due to stigma and/or face systemic and institutional barriers to service access (McLoughlin, 2013). Research with teachers reveals that the following warning signs may identify students who are homeless or at risk of homelessness (i.e., Thielking, La Sala \& Flatau, 2017). Based on the evidence, [INSERT name of school] will ensure that, in addition to student or family disclosure of homelessness, the following indicators will serve to act as a warning sign for possible intervention:

1 Uniform: students may not be wearing the right uniform, or they may be wearing the same uniform repeatedly and/or wearing a uniform that is noticeably unwashed or dishevelled

2 Attendance: students may be consistently arriving late to school or arriving very early to school and may have frequent non-attendance

3 Schoolwork: students may not be doing homework consistently or at all or are not able to keep up in class because of tiredness or distraction, and they may fall behind in classes

4 Hunger: students may not have lunch and other school snacks and no money for the school canteen

5 Mental health: students may display a severe decline in psychological wellbeing and/or an increase in behavioural issues or rule-breaking.

Thielking et al. (2017) p. 103

Teachers and other school staff may require professional development and training to competently and confidently respond to students with a history of trauma (Luthar \& Mendes, 2020). [INSERT name of school] continually ensures school staff have the knowledge and skills to provide a safe learning environment for all students, including those with a history of trauma and those who may be experiencing or be at risk of experiencing homelessness. [INSERT name of school] will collaborate with local specialist homelessness and mental health services to undergo such training. 
Establishment of effective school and community collaborations with the aim of keeping students safe at home or in supportive housing and at school

A school's role in the promotion of self-worth and belonging and in providing important reparative relationships for students facing difficult home circumstances cannot be underestimated (e.g., Moore \& McArthur, 2011). Schools must actively promote interprofessional collaboration, both within the school and with outside agencies, to ensure students have their needs met so they can experience educational success (Markward \& Biros, 2001).

[INSERT name of school] is committed to establishing formal collaborations with specialist homeless and other services in our community to assist in early intervention and access to appropriate services when students are experiencing homelessness or are at risk of homelessness.

Formal collaborations will be developed through the establishment of Memorandums of Understanding (MOU) with the following agencies/services:

[INSERT name of school] to list here (preferably) local services and agencies to ensure students who are experiencing homelessness or are at risk of homelessness are safe, remain at home or are placed in supportive housing so as to enable them to continue their education.

[INSERT name of school] will support collaborations by ensuring teachers and student wellbeing staff are provided with school leadership support and appropriate practical resources to participate in collaborations within the school and between the school and relevant agencies with the aim of keeping students safe at home or in supportive housing and/or at school (Thielking et al., 2017).

\section{Authorship}

Associate Professor Monica Thielking, Chair Department of Psychological Sciences, Swinburne University of Technology

[INSERT RELEVANT STAFF MEMBERS]

\section{Related policy and documents}

United Nations Convention on the Rights of the Child Universal Declaration of Human Rights

\section{Date of ratification}

This policy was ratified on the [INSERT DATE].

\section{Date of review}

This policy will be reviewed by [INSERT DATE]. 


\section{Rating of evidence base}

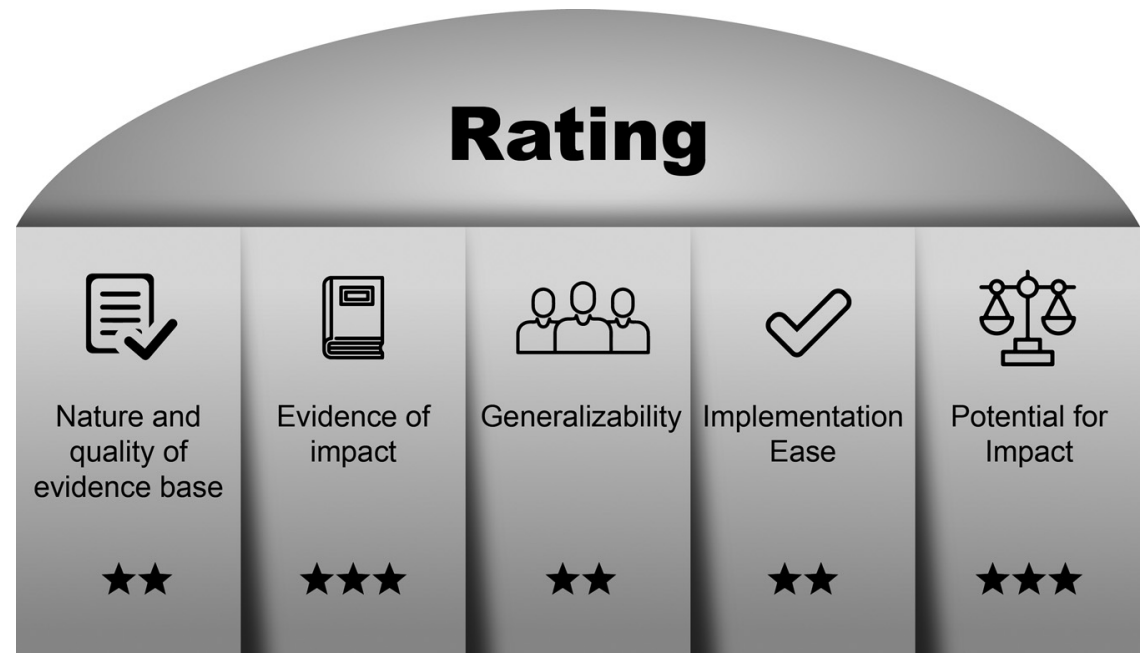

Figure 29.1. School and Community Collaborations to Prevent Student Homelessness Rating of Evidence.

Author Note. There is a need for more high-quality experimental research that trials the effectiveness of school collaborations on student outcomes. Most research on youth homelessness occurs in UK, US and Australian contexts and may not be generalisable to other cultures. The policy requires leadership via a school and community working group to support the establishment of formal partnerships and ongoing collaborations. By schools recognising that student homelessness exists, working in collaboration with community agencies, equipping teachers and school staff with the resources and connections to intervene effectively, and aiming to keep students safe at home or in supportive housing and at school, there is a high likelihood of impact.

\section{Expert consultation}

Consultation with academic, cultural and content experts may be required to enact the policy. Community, student or family stakeholder input and specific school-level requirements would ensure the policy is relevant and appropriate to the school setting and community. Consultation with teachers, the school psychologist and other wellbeing teams is required. As this policy deals with student issues where there may be a high risk of possible neglect, maltreatment or abuse, always ensure that statutory mandatory reporting requirements are adhered to.

\section{References}

Australian Bureau of Statistics. (2016). Information paper - A statistical definition of homelessness, 2016 (cat. no. 2049.0). https://www.abs.gov.au/statistics/people/housing/ census-population-and-housing-estimating-homelessness/latest-release\#data-download 
Cutuli, J. J. (2018). Homelessness in high school: population-representative rates of self-reported homelessness, resilience, and risk in Philadelphia. Social Work Research, 42(3), 159-168.

Flatau, P., Thielking, M., MacKenzie, D., \& Steen, A. (2015). The Cost of Youth Homelessness in Australia Study: Snapshot Report 1. Swinburne Institute for Social Research, Salvation Army Australia, Mission Australia, Anglicare Australia, Centre for Social Impact. https://apo.org.au/sites/default/files/resource-files/2015-02/apo-nid53029.pdf

Gultekin, L. E., Brush, B. L., Ginier, E., Cordom, A., \& Dowdell, E. B. (2020). Health risks and outcomes of homelessness in school-age children and youth: A scoping review of the literature. The Journal of School Nursing, 36(1), 10-18.

Hong, S., \& Piescher, K. (2012). The role of supportive housing in homeless children's well-being: An investigation of child welfare and educational outcomes. Children and Youth Services Review, 34(8), 1440-1447.

Institute for Children, Poverty and Homelessness [ICPH]. (2020). The United States of homelessness. ICPH. https://www.icphusa.org/interactive_data/the-united-states-ofhomelessness/

Low, J. A., Hallett, R. E., \& Mo, E. (2017). Doubled-up homeless: Comparing educational outcomes with low-income students. Education and Urban Society, 49(9), 795-813.

Markward, M. J., \& Biros, E. (2001). McKinney revisited: Implications for school social work. Children \& Schools, 23(3), 182-187.

McLoughlin, P. J. (2013). Couch surfing on the margins: the reliance on temporary living arrangements as a form of homelessness amongst school-aged home leavers. Journal of Youth Studies, 16(4), 521-545.

Moore, T., \& McArthur, M. (2011). "Good for kids": Children who have been homeless talk about school. Australian Journal of Education, 55(2), 147-160.

Moore, H., et al. (2019). A statewide study of school-based victimization, discriminatory bullying, and weapon victimization by student homelessness status. Social Work Research, 43(3), 181-194.

Moore, H., Benbenishty, R., Astor, R. A., \& Rice, E. (2018). The positive role of school climate on school victimization, depression, and suicidal ideation among school-attending homeless youth. Journal of School Violence, 17(3), 298-310.

National Youth Commission. (2008). Australia's homeless youth: a report of the National Youth Commission inquiry into youth homelessness. https://apo.org.au/ node/8435

Organisation for Economic Co-operation and Development [OECD]. (2020). Hc3.1 Homeless population. https://www.oecd.org/els/family/HC3-1-Homeless-population. pdf

Office of the United Nations High Commissioner for Human Rights [UNHCR]. (1989). UN convention on the rights of the child. http://www2.ohchr.org/english/law/ crc.htm

Sanders, B., \& Brown, B. (2015). "I was all on my own”: experiences of loneliness and isolation amongst homeless people. Crisis. https://www.crisis.org.uk/media/20504/ crisis_i_was_all_on_my_own_2016.pdf

Stone, S. I., \& Charles, J. (2018). Conceptualizing the problems and possibilities of interprofessional collaboration in schools. Children \& Schools, 40(3), 185-192.

Sulkowski, M. L., \& Michael, K. (2014). Meeting the mental health needs of homeless students in schools: A multi-tiered system of support framework. Children and Youth Services Review, 44, 145-151. 


\section{Thielking}

Luthar, S. S., \& Mendes, S. H. (2020) Trauma-informed schools: Supporting educators as they support the children. International Journal of School \& Educational Psychology, 8(2), 147-157.

Thielking, M., Flatau, P., La Sala, L., \& Sutton, D. (2015). Couch surfing secondary students: The Yarra Ranges youth homelessness prevention project. https://www. csi.edu.au/research/project/couchsurfing-students-yarra-ranges-youth-homelessnessprevention-project/

Thielking, M., La Sala, L., \& Flatau, P. (2017). The role of teachers in identifying and supporting homeless secondary school students: Important lessons for teacher education. Australian Journal of Teacher Education, 42(8), 95-109.

Thielking, M., Skues, J., \& Le, V. (2018). Collaborative practices among Australian school psychologists, guidance officers and school counsellors: Important lessons for school psychological practice. Educational \& Developmental Psychologist, 35(1), $18-35$.

Tyler, K. A., \& Schmitz, R. M. (2020). Childhood disadvantage, social and psychological stress, and substance use among homeless youth: A life stress framework. Youth \& Society, 52(2), 272-287.

United Nations General Assembly. (1948). Universal declaration of human rights. UN General Assembly, 302(2).

Williams, P., \& Sullivan, H. (2009). Faces of integration. International Journal of Integrated Care, 9(5), 1-13. 